\title{
Study of the parameters influencing the co-grinding process for the production of meloxicam nanoparticles
}

\author{
Levente Kürti a,c , Ákos Kukovecz ${ }^{\text {b }}$, Gábor Kozma ${ }^{\text {b }}$, Rita Ambrus a , Mária A. Deli c, Piroska Szabó-Révész ${ }^{\text {a,* }}$ \\ a Department of Pharmaceutical Technology, University of Szeged, Szeged, Hungary \\ ${ }^{b}$ Department of Applied E Environmental Chemistry, University of Szeged, Szeged, Hungary \\ c Laboratory of Molecular Neurobiology, Institute of Biophysics, Biological Research Centre, Hungarian Academy of Sciences, Szeged, Hungary
}

\section{A R T I C L E I N F O}

\section{Article history:}

Received 9 July 2010

Received in revised form 31 March 2011

Accepted 21 May 2011

Available online 1 June 2011

\section{Keywords:}

Nanoparticle

Meloxicam

Co-grinding

Scanning electron microscopy

Factorial experimental design

Nasal powder system

\begin{abstract}
A B S T R A C T
Co-grinding is a procedure for the preparation of nanoparticles in which the drug is ground together with one or more excipients. The grinding of meloxicam, a crystalline solid, together with amorphous polyvinylpyrrolidone (PVP) or semi-crystalline polyethylene glycol (PEG) as excipients, is expected to lead to a drastic reduction in particle size. We optimized meloxicam grinding using a three level full factorial response surface design. In the case of PVP the optimum co-grinding parameter set in our study proved to be a meloxicam to PVP-C30 ratio of $1: 1$, and a rotation frequency of $400 \mathrm{rpm}$. The best size reduction was achieved at a meloxicam to PEG 6000 ratio $=1: 2$ at a rotation frequency of $400 \mathrm{rpm}$ : nanoparticles averaging $\mathrm{d}_{\mathrm{SEM}}=174 \mathrm{~nm}$ in diameter and with a very narrow size distribution (standard deviation $35 \%$ of mean) were obtained. X-ray powder diffraction analysis indicated that the optimized products contained amorphous meloxicam nanoparticles in the PVP-C30 composition, although meloxicam nanocrystals could also be detected in the samples which contained PEG 6000. The dissolution properties were significantly increased under nasal conditions ( $\mathrm{pH} 5.1$, temperature $30^{\circ} \mathrm{C}$ ), especially in the case of the amorphous product. Such dry powder systems can offer novel opportunities in systemic nasal drug delivery.
\end{abstract}

(c) 2011 Elsevier B.V. All rights reserved.

\section{Introduction}

Nanonization offers an excellent possibility to overcome mucosal barriers [1,2] and has several advantages in drug delivery [3,4]. It is believed that nanoparticles can be transported across barriers into the bloodstream without prior dissolution [5]. Nano-sized drugs with carriers can overcome the resistance offered by the physiological barriers in the body because the efficient delivery of drugs to various parts of the body is directly affected by the particle size [6].

Several techniques are available for the production of drug nanoparticles [7]. Basically, bottom-up and top-down technologies can be differentiated. The bottom-up technologies start from the molecules, which are precipitated (crystallized) in a controlled fashion to yield the desired particle size. Nowadays, bottom-up techniques are not the main choice for drug nanoparticle production due to the use of organic solvents. The top-down technologies are disintegration methods e.g. various types of milling (high-intensity ultrasonication, high-pressure homogenization, grinding or co-grinding) are more frequently used [8].

The size reduction of pharmaceutical materials is often performed by means of dry milling $[9,10]$, but the size reduction possible by dry

\footnotetext{
* Corresponding author at: H-6720 Eötvös utca 6., Szeged, Hungary. Tel.: + 3662 545572; fax: + 3662545571 .

E-mail address: revesz@pharm.u-szeged.hu (P. Szabó-Révész).
}

milling is known to be limited to around $3 \mu \mathrm{m}$ due to aggregation of the particles. Experiments focusing on a particle size reduction to the submicron region by co-grinding with additives have recently been attempted [11-14].

Nanonization has become a popular approach to produce particles in the size range of $200-400 \mathrm{~nm}$, to improve both the dissolution rate and the solubility of the compound [15]. The latter phenomenon is due to the well-known dependency of solubility on particle size as described by the Ostwald-Freundlich equation. Breakage of micronsized drug crystals into nanoparticles creates an increased particle surface area, which is thermodynamically unfavorable. Thus, nanosized particles tend to agglomerate to reduce their surface area. Particle agglomeration can be prevented by steric stabilization using polymeric excipients [16].

Co-grinding is a top-down disintegration procedure for the preparation of nanoparticles by grinding of the drug together with one or more excipients $[17,18]$. A main advantage of co-grinding as compared to other methods is that it is a simple procedure and organic solvents are not needed for the preparation of nanoparticles; it is therefore an economically and environmentally desirable technology [19]. It is important to control the parameters (e.g. duration of grinding, the grinding rate, the material and the volume of the grinding pot, the material and the number of the grinding balls, the grinding excipients and the drug/excipient ratio) by means of a factorial experimental design $[20,21]$. 
Meloxicam, a non-steroidal anti-inflammatory and analgesic water-insoluble drug (NSAID), is an enolic acid oxicam derivative $[22,23]$. The single oral dose of meloxicam is $7.5-15 \mathrm{mg}$. The favorable side-effect profile and the low quantity of a single dose make this NSAID suitable for administration via alternative pathways, e.g. intranasally. This may result in novel opportunities for the easing of pain, which affects the region of the head.

A reduction of the particle size of meloxicam into the nano-size range $(100-1000 \mathrm{~nm})$ is possible by crystallization methods through formulation of the drug in a nanosuspension [24]. However, cogrinding offers a simpler and environmentally friendly way of preparing meloxicam nanoparticles. Nanoparticles are a formulation principle for all poorly soluble drugs for which the dissolution velocity is the rate limiting step for absorption and thus the reason for a too low bioavailability. The increase in surface area leads to an increase in the dissolution velocity.

Water-soluble polymers have typically been used as co-grinding excipients $[13,25,26]$. An example is polyvinylpyrrolidone (PVP), an amorphous excipient which does not melt during the grinding process therefore it could also help particle size reduction and to prevent the agglomeration, as stabilizer agent [27-29]. On the contrary, polyethylene glycol (PEG) is a semicrystalline grinding excipient with low melting point which could melt due to friction work and as a consequence it cannot help as efficiently as PVP the size reduction.

The grinding of meloxicam, a crystalline solid, together with amorphous PVP or semicrystalline PEG as excipients is expected to lead to a drastic reduction in particle size and to possible changes in the crystallinity of meloxicam without any harmful alterations in its pharmaceutical effect. The crystalline and the amorphous form of an active agent have no difference in their effect, although the onset of action can be improved with faster dissolution rate.

Multivariate problems similar to meloxicam grinding are often optimized by using the COST (Change One Separate factor at a Time) approach: all parameters but one are fixed, and the response of the system is studied as a function of the changing variable. Each variable is scanned in this way, and the combination of their optimum values is accepted as the overall optimum. Unfortunately, this method is slow, since the number of necessary experiments increases considerably with the number of variables. Moreover, the COST approach can seldom find the true overall optimum of a system since it assumes that the effects of all variables are completely independent, whereas the response of a real system to change in any single parameter often appears as the overall effect of several parameter alterations (i.e. reallife multidimensional parameter spaces are seldom orthogonal). A good strategy for finding the overall optimum of a multivariate problem is to fit the response surface on the basis of the responses obtained from well-chosen parameter sets. Since the effect of any single variable can usually be accounted for by a second-order polynomial, it is customary to test parameters at three different levels: a high, a medium and a low setting. Such designs, called three-level full factorial designs, have been applied successfully in the past to optimize the synthesis of carbon nanotubes [20,30], the deposition of titanate nanowires on glass [31] and the wet peroxidation of aqueous phenol solution [32]. The simplest three-level full factorial design is to pick three values for one independent variable $\left(\mathrm{x}_{1}\right.$ : rotation speed), chart the three corresponding response (d: particle diameter) values in a standard two dimensional Cartesian coordinate system and fit the $\mathrm{d}=\mathrm{f}\left(\mathrm{x}_{1}\right)$ function by a parabola. In case of two independent variables $\left(\mathrm{x}_{1}\right.$ : rotation speed and $\mathrm{x}_{2}$ : meloxicam to excipient ratio) we need to sample $3 \times 3=9$ points in the $x_{1} x_{2}$ plane and chart the corresponding $\mathrm{d}$ values as elevation above the $\mathrm{x}_{1} \mathrm{x}_{2}$ plane in a three dimensional coordinate system.

The aim of our present research work was to produce meloxicam nanoparticles by co-grinding process with PVP and PEG, investigating the influence of different parameters on particle size and optimizing them by using a three-level full factorial design so that nano-sized meloxicam particles of uniform size distribution are obtained. The optimized products were investigated from the aspects of crystallinity and extent of dissolution under in vitro nasal circumstances.

\section{Materials and methods}

\subsection{Materials}

Meloxicam (4-hydroxy-2-methyl- $\mathrm{N}$-(5-methyl-2-thiazolyl)-2Hbenzothiazine-3-carboxamide-1,1-dioxide) was obtained from EGIS Ltd. (Budapest, Hungary). The grinding additives, polyvinylpyrrolidone (PVP) K25 and C30 were purchased from BASF (Ludwigshafen, Germany). Types of PVP (K25 and C30) differ in molecular weight, viscosity and field of application. Molecular weight of PVP-K25 is about 34,000 and PVP-C30 has a higher molecular weight (about 58,000 ). Because their viscosity relating to molecular weight so the viscosity of PVP-C30 is higher, than for K25. In the case of PVP the letter " $C$ " indicates applicability also for preparation of aseptic dosage forms. Polyethylene glycol (PEG) 6000 and 20,000 were from SigmaAldrich Chemie GmbH, Germany. The numbers of PEG (6000 and 20,000 ) refer to the molecular weight of the polymer.

\subsection{Methods}

\subsubsection{Preliminary experiments}

Several pharmaceutical excipients were tested, and the results of the co-grinding of meloxicam with PVP and PEG were the most promising in the aspect of particle size reduction. In these preliminary experiments some optimum parameters of the grinding (the duration of grinding, the material and the volume of the grinding pot and the material and the number of grinding balls) were also set.

\subsubsection{Preparation of co-ground formulations and their physical mixtures}

Binary mixtures of as-received meloxicam powder and the carriers PVP-C30, PVP-K25, PEG 6000 and PEG 20,000 were mixed and charged into the chamber of the planetary monomill (Fritsch Pulverisette 6, Fritsch $\mathrm{GmbH}$, Idar-Oberstein, Germany) in various drug-carrier ratios (1:0.5, $1: 1$ and $1: 2)$. The grinding was performed in an $80 \mathrm{~cm}^{3}$ silicon nitride $\left(\mathrm{Si}_{3} \mathrm{~N}_{4}\right)$ milling drum containing 25 silicon nitride balls $10 \mathrm{~mm}$ in diameter. In each experiment, $1.0 \mathrm{~g}$ of meloxicam was ground together with the calculated amount of polymer additive.

The milling parameters are given in Table 1 and the investigated parameters are listed in Table 2. After grinding, the samples were stored in plastic vials until use.

The physical mixtures of drug-carrier were prepared by accurately weighing the calculated amounts of meloxicam and carrier, mixing them well in a porcelain mortar and storing in plastic vials until use.

\subsubsection{Determination of particle size by scanning electron microscopic image analysis}

2.2.3.1. Scanning electron microscopy (SEM). Co-ground products were washed and centrifuged three times in distilled water to separate the water-soluble excipient from the water-insoluble meloxicam (the solubility of meloxicam is $4.4 \pm 0.7 \mu \mathrm{g} / \mathrm{mL}$ [24]), so that individual meloxicam particles could be studied. The particle size and the surface

Table 1

General parameters of co-grinding, independent variables.

\begin{tabular}{ll}
\hline Material of the grinding pot & $\mathrm{Si}_{3} \mathrm{~N}_{4}$ \\
Material of the grinding balls & $\mathrm{Si}_{3} \mathrm{~N}_{4}$ \\
Number of the grinding balls & 25 \\
$\mathrm{~V}_{\text {grinding pot }}$ & $80 \mathrm{~mL}$ \\
D grinding ball & $10 \mathrm{~mm}$ \\
$t_{\text {milling }}$ & $2 \mathrm{~h}$ \\
\hline
\end{tabular}


Table 2

Compositions of different samples, parameters of optimization.

\begin{tabular}{ll} 
Meloxicam/excipient ratio & $1: 0.5,1: 1,1: 2$ \\
Excipients & PVP-C30, PVP-K25, PEG 6000, PEG 20,000 \\
Revolutions per minute (rpm) & $200,300,400$ \\
\hline
\end{tabular}

morphology of the meloxicam particles were visualized by SEM. Samples were fixed onto a metallic stub with double-sided conductive tape (diameter $12 \mathrm{~mm}$, Oxon, Oxford Instruments, UK). Images were taken in secondary electron image mode on a Hitachi S-4700 Type II instrument at an acceleration voltage of $10 \mathrm{kV}$.

2.2.3.2. Image analysis. Meloxicam particle diameter distributions were obtained by analyzing several SEM images with the Image software environment [33]. Over 150 individual particle measurements were made in at least five different images in order to determine the particle size accurately. Although less frequently used than TEM or dynamic light scattering, SEM image analysis is an established method for nanoparticle size analysis: for instance, it was applied successfully for the characterization of carbon nanotube networks [30], Zn-glycerolate microstacks [34] and co-grinding products of PVP and $\mathrm{CaCO}_{3}$ [35].

2.2.3.3. Design of experiments. In a series of pre-screening experiments the following parameters were fixed (see Table 1): (i) the milling drum size and material, (ii) the ball size and number, and (iii) the milling duration. The remaining variables, i.e. the excipient type, the excipient-to-meloxicam ratio and the milling rate were the parameters featuring in the optimization. A full factorial design plan was created and carried out with the meloxicam particle size distribution defined as response factor. All calculations were performed by using Minitab 14 (Minitab Statistical Software).

\subsubsection{Further investigations of the optimized products}

2.2.4.1. X-ray powder diffraction analysis (XRPD). The physical state of meloxicam in the different samples was evaluated by XRPD. Diffraction patterns were analyzed with a Miniflex II X-ray Diffractometer (Rigaku Co. Tokyo, Japan), where the tube anode was Cu with $\mathrm{K} \alpha=1.5405 \AA$. The pattern was collected with a tube voltage of $30 \mathrm{kV}$ and a tube current of $15 \mathrm{~mA}$ in in-step scan mode $\left(4^{\circ} / \mathrm{min}\right)$. The instrument was calibrated by using $\mathrm{Si}$.

2.2.4.2. Studies of the extent of dissolution under in vitro nasal conditions. The dissolution of different powder samples containing the same amount of drug $(10 \mathrm{mg})$ was determined according to the European Pharmacopoeia (6th Edition) paddle method (Pharma test, Heinburg, Germany), which means a rotating paddle in the dissolution vessel. $50.0 \mathrm{~mL}$ of phosphate buffer solution $(\mathrm{pH} 5.6 \pm 0.1)$ at $30 \pm 0.5^{\circ} \mathrm{C}$ was used as a dissolution medium and the rotation speed of the paddles was $100 \mathrm{rpm}$. At predetermined times, $1 \mathrm{~mL}$ samples were withdrawn and immediately filtered (cut-off $0.2 \mu \mathrm{m}$, Minisart SRP 25, Sartorius, Germany) and the amount of dissolved drug was determined spectrophotometrically $(\lambda=364 \mathrm{~nm})$. Withdrawn samples were replaced with $1 \mathrm{~mL}$ of fresh medium.

\section{Results and discussion}

Fig. 1 presents typical SEM images of meloxicam particles before grinding (A) and after grinding in the presence of the various excipients (B-D). The particle size was reduced by roughly one order of magnitude, regardless of the additive used. This primary effect originated from the high-energy collisions taking place in the planetary ball mill [36]. Ball milling is a process with complex mechanics, analyzed in detail by Chattopadhyay et al. [37]. On the basis of their model, it was possible to calculate the energetics of the co-grinding experiments performed. The results in Table 3 indicate
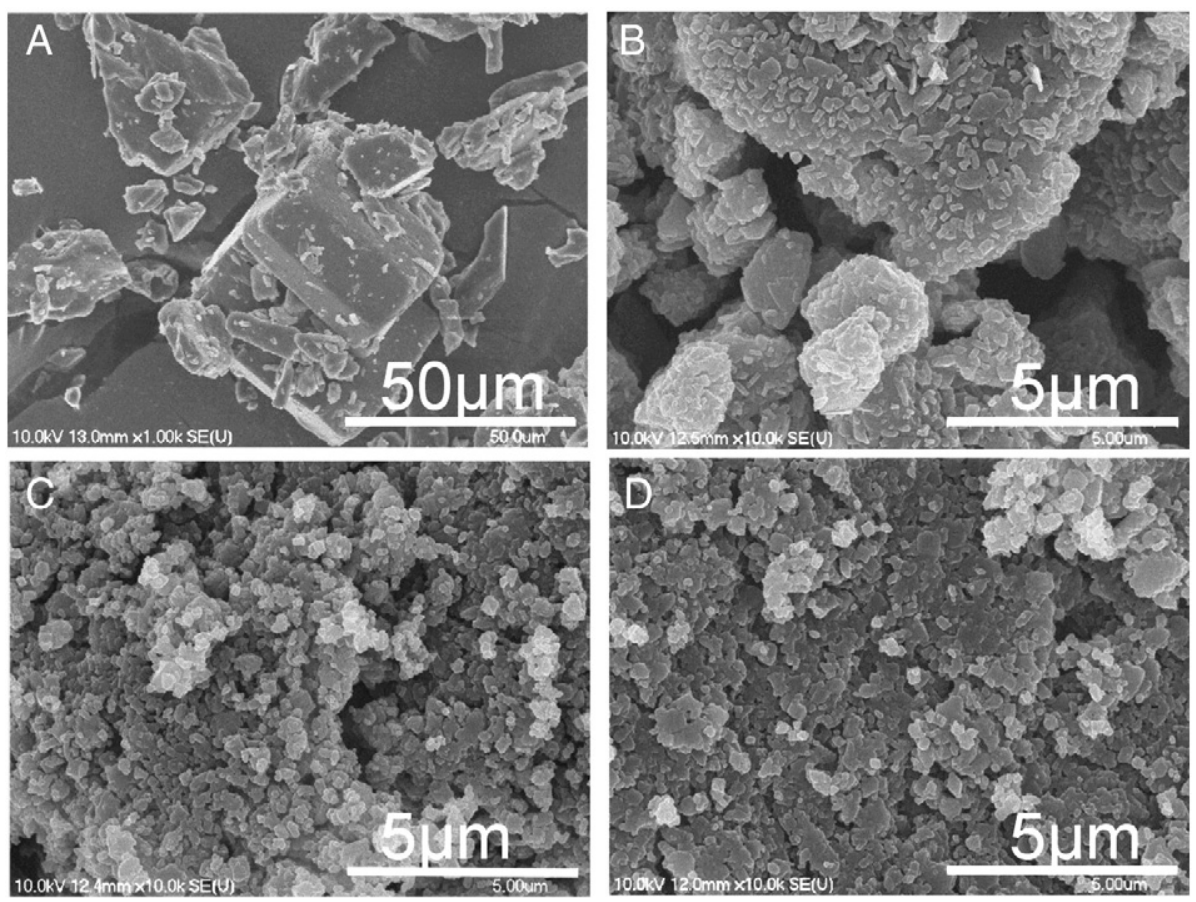

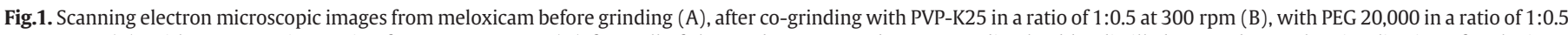

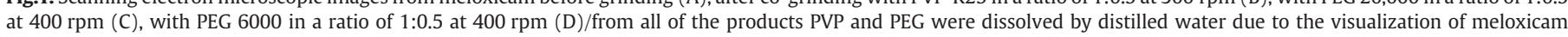
particles/. 
Table 3

Milling energetics map of the experiments performed.

\begin{tabular}{|c|c|c|c|c|c|}
\hline \multirow[b]{3}{*}{$\begin{array}{l}\text { Rotation } \\
\text { speed (rpm) }\end{array}$} & \multirow[b]{3}{*}{$\begin{array}{l}\text { Collision } \\
\text { frequency }\left(s^{-1}\right)\end{array}$} & \multirow{2}{*}{\multicolumn{4}{|c|}{$\begin{array}{l}\text { Cumulative collision energy transferred } \\
\left(\mathrm{kJ} \cdot \mathrm{g}^{-1}\right) \\
\text { Meloxicam to additive weight ratio }\end{array}$}} \\
\hline & & & & & \\
\hline & & No additive & $1: 0.5$ & $1: 1$ & $1: 2$ \\
\hline 200 & 240 & 8.56 & 5.71 & 4.28 & 2.85 \\
\hline 300 & 360 & 28.89 & 19.27 & 14.45 & 9.63 \\
\hline 400 & 480 & 68.50 & 45.67 & 34.25 & 22.83 \\
\hline
\end{tabular}

that the total energy transferred to the meloxicam-excipient mixture via collisions in our system lies in the range of $2.80-68.50 \mathrm{kJg}^{-1}$.

A closer analysis of the SEM micrographs revealed that there were considerable differences in nanoparticle size distribution as a function of the excipient type used. The size distribution function is characterized by the mean particle diameter and the standard deviation of the diameter (given as a percentage of the mean and denoted as SD\%). These values are reported in Table 4, and their relationship with the grinding variables is analyzed quantitatively in the main effects plots (Figs. 2 and 3) and interaction plots (Figs. 4 and 5). The main effects plot shows the average response for each value of each variable, combining the effects of the other variables as if all variables were independent. The main effects plots for the meloxicam particle diameter indicate that the tested excipients can all promote size reduction (Fig. 2). Increasing the relative amount of meloxicam in the system resulted in larger product particles, whereas increasing the milling energy (grinding rate) reduced the particle size. Since our goal was to grind meloxicam into uniformly small particles so that its administration can be controlled, it was important to study the main effects plots characterizing the broadness of the particle size distribution curve (SD\%) (Fig. 3). It is evident from Fig. 3 that the excipients PVP-K25 and PEG 6000 provide significantly broader and narrower diameter distributions, respectively, than the other two tested additives. Increase of the meloxicam to additive ratio resulted in a less uniform product. On the other hand, the distribution uniformity as a function of the milling energy exhibited a minimum at $300 \mathrm{rpm}$.

Interaction plots illustrate the effects between variables, which are not independent by showing the means of the responses for each level of a factor for each level of a second factor pairwise for all factors involved in the study. Therefore, the interaction plots presented in Figs. 4 and 5 for the mean diameter and the SD\%, respectively, can be used to gain insight into the complex interactions between the grinding parameters. For example: (i) all additives but PVP-C30 result in a particle diameter increase at higher milling rates, (ii) increasing the milling frequency can compensate the diameter differences introduced by changing the meloxicam to additive ratio, (iii) the use of PEG 6000 as additive results in particularly narrow size distributions, regardless of the choice of the other two parameters, etc.

We are now in a position to summarize the grinding behavior of the novel NSAID meloxicam in a high-energy ball mill with $\mathrm{Si}_{3} \mathrm{~N}_{4}$ as grinding material. In the absence of any grinding additives, the final product particles are too large at low milling energy $\left(d_{\text {SEM }}=364 \mathrm{~nm}\right.$ at $200 \mathrm{rpm})$ and aggregate rapidly at high energy $\left(\mathrm{d}_{\mathrm{SEM}}=343 \mathrm{~nm}\right.$ at $400 \mathrm{rpm}$ ). There is an optimum at $300 \mathrm{rpm}$. However, even at this setting, the average product particle size is above $d_{\text {SEM }}=270 \mathrm{~nm}$. It is interesting to note that, without additives, the relative broadness of the particle size distribution function was independent of the milling energy (SD 61\%).

With PVP-C30, it was possible to push the average meloxicam particle size below $250 \mathrm{~nm}$ and the average SD below $50 \%$. This was a significant improvement relative to the additive-free grinding result. The optimum co-grinding parameter set for PVP-C30 was a meloxicam to excipient ratio $=1: 1$, and a rotation frequency of $400 \mathrm{rpm}$.
Table 4

Particle diameter $\left(\mathrm{d}_{\mathrm{SEM}}\right)$ of meloxicam particles in different compositions.

\begin{tabular}{|c|c|c|c|}
\hline Excipient & Meloxicam/excipient ratio & Rotation speed (rpm) & $\mathrm{d}_{\mathrm{SEM}} \pm \mathrm{SD}(\mathrm{nm})$ \\
\hline- & $1: 0$ & - & $2643.6 \pm 2629.1$ \\
\hline- & $1: 0$ & 200 & $364.5 \pm 228.1$ \\
\hline- & $1: 0$ & 300 & $275.0 \pm 170.6$ \\
\hline- & $1: 0$ & 400 & $343.5 \pm 205.9$ \\
\hline PVP-C30 & $1: 0.5$ & 200 & $511 \pm 333$ \\
\hline PVP-C30 & $1: 1$ & 200 & $267 \pm 158$ \\
\hline PVP-C30 & $1: 2$ & 200 & $221.7 \pm 105.4$ \\
\hline PVP-C30 & $1: 0.5$ & 300 & $243 \pm 115$ \\
\hline PVP-C30 & $1: 1$ & 300 & $242 \pm 141$ \\
\hline PVP-C30 & $1: 2$ & 300 & $302.3 \pm 115.7$ \\
\hline PVP-C30 & $1: 0.5$ & 400 & $209.9 \pm 85.3$ \\
\hline PVP-C30 & $1: 1$ & 400 & $140.4 \pm 69.2$ \\
\hline PVP-C30 & $1: 2$ & 400 & $238.6 \pm 147.9$ \\
\hline PVP-K25 & $1: 0.5$ & 200 & $203.6 \pm 190.0$ \\
\hline PVP-K25 & $1: 1$ & 200 & $192.7 \pm 74.4$ \\
\hline PVP-K25 & $1: 2$ & 200 & $229.1 \pm 203.2$ \\
\hline PVP-K25 & $1: 0.5$ & 300 & $266.3 \pm 117.0$ \\
\hline PVP-K25 & $1: 1$ & 300 & $351.7 \pm 227.7$ \\
\hline PVP-K25 & $1: 2$ & 300 & $277.6 \pm 139.9$ \\
\hline PVP-K25 & $1: 0.5$ & 400 & $251.5 \pm 362.6$ \\
\hline PVP-K25 & $1: 1$ & 400 & $246.4 \pm 108.5$ \\
\hline PVP-K25 & $1: 2$ & 400 & $262.8 \pm 124.7$ \\
\hline PEG 6000 & $1: 0.5$ & 200 & $175.2 \pm 57.4$ \\
\hline PEG 6000 & $1: 1$ & 200 & $212.3 \pm 92.0$ \\
\hline PEG 6000 & $1: 2$ & 200 & - \\
\hline PEG 6000 & $1: 0.5$ & 300 & $165.0 \pm 59.6$ \\
\hline PEG 6000 & $1: 1$ & 300 & $204.4 \pm 88.9$ \\
\hline PEG 6000 & $1: 2$ & 300 & $358.1 \pm 145.3$ \\
\hline PEG 6000 & $1: 0.5$ & 400 & $197.3 \pm 84.8$ \\
\hline PEG 6000 & $1: 1$ & 400 & $229.5 \pm 92.3$ \\
\hline PEG 6000 & $1: 2$ & 400 & $173.8 \pm 60.3$ \\
\hline PEG 20,000 & $1: 0.5$ & 200 & $368.7 \pm 238.0$ \\
\hline PEG 20,000 & $1: 1$ & 200 & $318.8 \pm 136.2$ \\
\hline PEG 20,000 & $1: 2$ & 200 & $200.0 \pm 134.6$ \\
\hline PEG 20,000 & $1: 0.5$ & 300 & $235.5 \pm 117.7$ \\
\hline PEG 20,000 & $1: 1$ & 300 & $217.6 \pm 103.7$ \\
\hline PEG 20,000 & $1: 2$ & 300 & - \\
\hline PEG 20,000 & $1: 0.5$ & 400 & $185.1 \pm 73.7$ \\
\hline PEG 20,000 & $1: 1$ & 400 & $234.5 \pm 122.9$ \\
\hline PEG 20,000 & $1: 2$ & 400 & $333.8 \pm 151.0$ \\
\hline
\end{tabular}

If the target drug administration task allows the application of PEG 6000 as additive, then it is possible to improve the co-grinding process further. The parameter setting meloxicam to PEG $6000=1: 2$ at a rotation frequency of $400 \mathrm{rpm}$ yields nanoparticles averaging $\mathrm{d}_{\mathrm{SEM}}=174 \mathrm{~nm}$ in diameter and a very narrow size distribution, characterized by $\mathrm{SD}=35 \%$. This set is the overall optimum result in our study.

The most promising products of the co-grinding process were further investigated by XRPD analysis. The optimized products (Table 5, Fig. 6) differ in their crystallinity, which can be observed in the diffraction spectra (Fig. 7). The XRPD patterns of meloxicam, physical mixtures and products containing meloxicam and excipients in the optimized ratio are presented. The presence of numerous distinct peaks in the XRPD spectrum indicates that meloxicam is a crystalline material; its characteristic peaks appear at diffraction angles $2 \Theta$ of $13.22,15.06,26.46$ and $26.67^{\circ}$. The crystallinity of meloxicam was decreased in the co-grinding process with PVP-C30; in the other optimized product, which contains PEG 6000 the crystallinity of meloxicam did not change significantly comparing to the physical mixture. The crystalline meloxicam was altered in the cogrinding process with the amorphous excipient, PVP-C30, leading to amorphous nanoparticles. With PEG 6000 as excipient, the crystallinity of meloxicam was proved (Fig. 7), i.e. meloxicam nanocrystals were prepared.

The extent of dissolution was determined under conditions of nasal drug delivery (Fig. 8). Under in vitro circumstances, we attempted to mimic the physiological conditions of the human nose; the temperature of the dissolution medium was $30{ }^{\circ} \mathrm{C}$ and the 

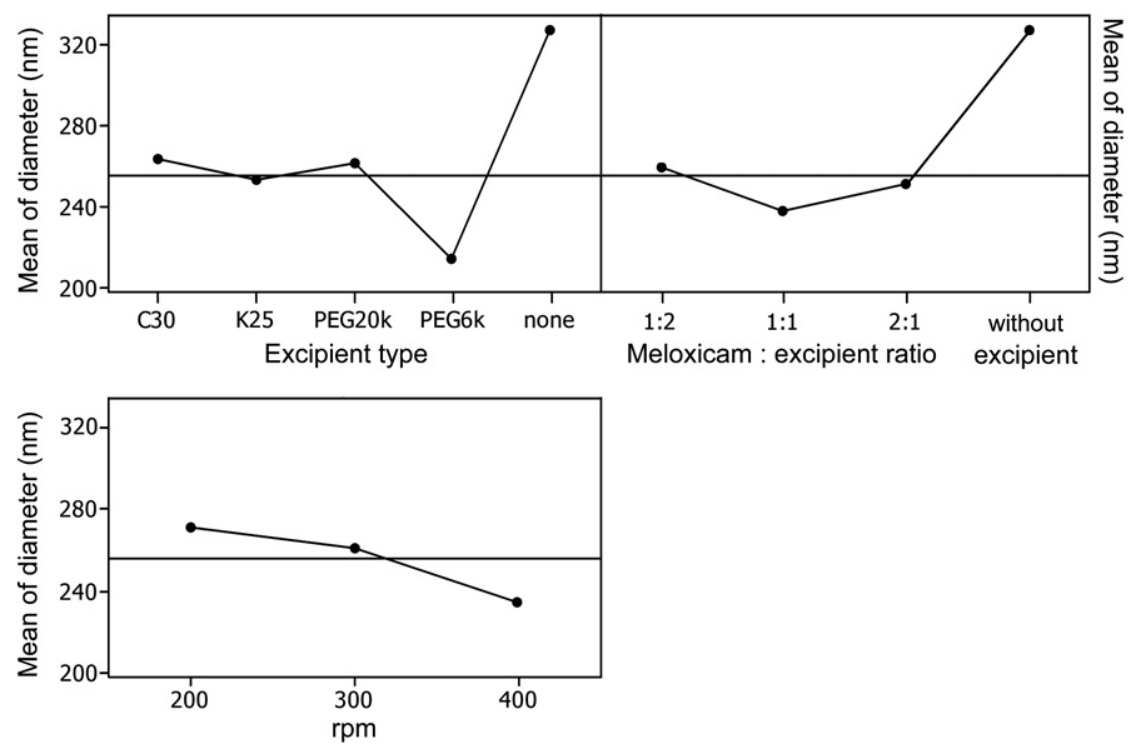

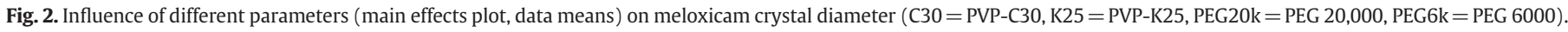
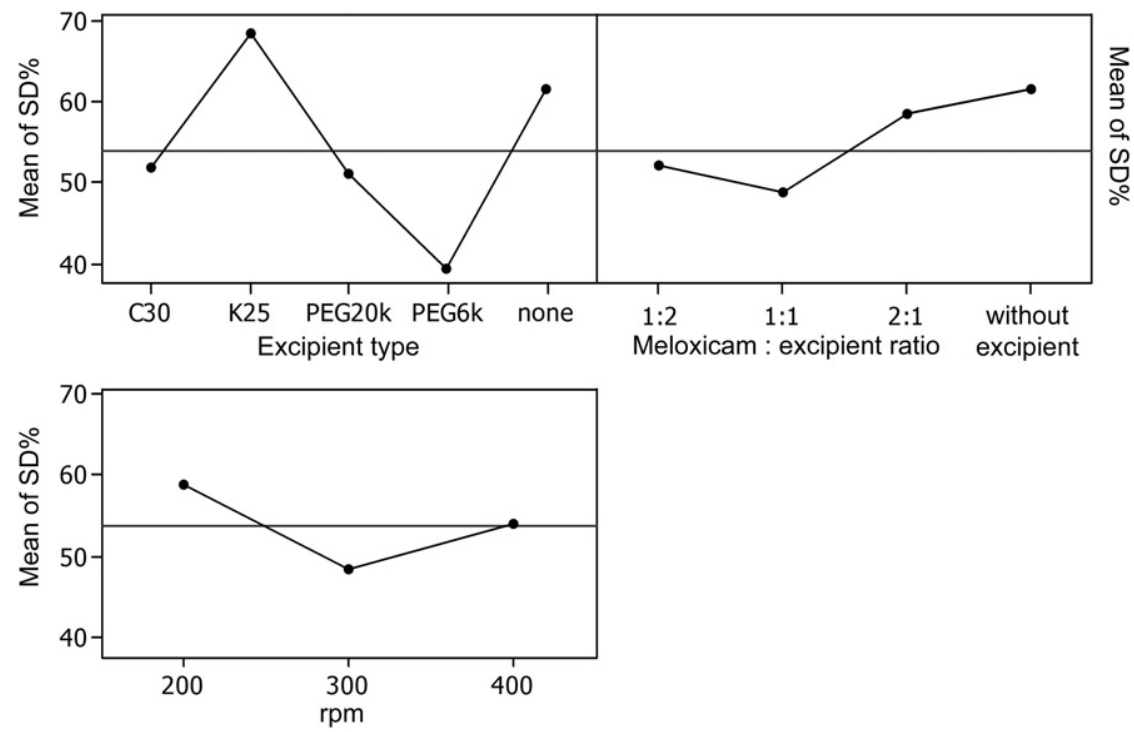

Fig. 3. Main effects plot (data means) for SD\% (C30= PVP-C30, K25=PVP-K25, PEG20k=PEG 20,000, PEG6k= PEG 6000).

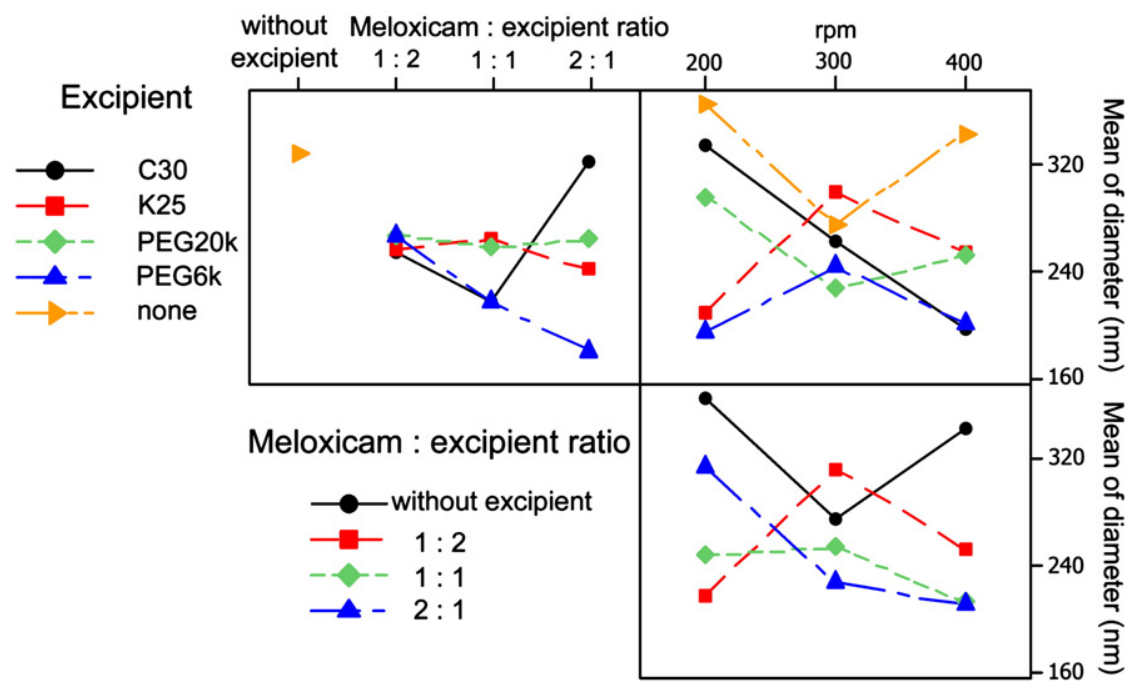

Fig. 4. Interaction plot (data means) for diameter (C30 = PVP-C30, K25 = PVP-K25, PEG20k $=$ PEG 20,000, PEG6k=PEG 6000) 


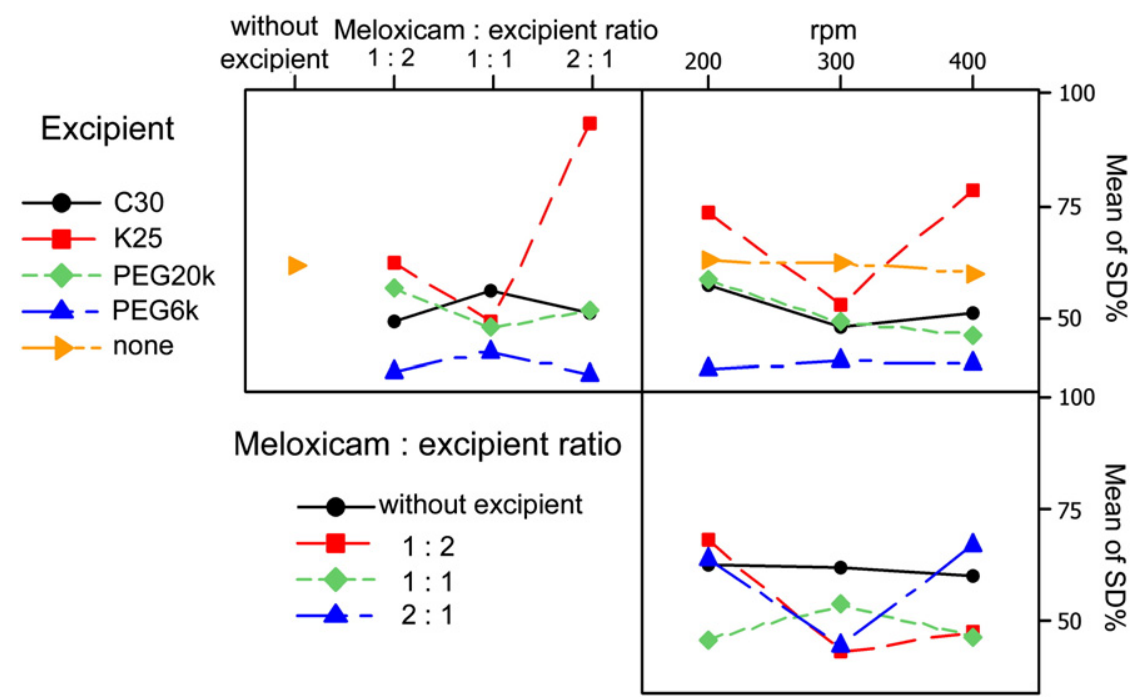

Fig. 5. Interaction plot (data means) for SD $\%(C 30=$ PVP-C30, K25 = PVP-K25, PEG20k=PEG 20,000, PEG6k= PEG 6000).

Table 5

Optimized products.

\begin{tabular}{lll}
\hline Grinding excipient of meloxicam & Drug to excipient ratio & Rotation speed (rpm) \\
\hline PVP-C30 & $1: 1$ & 400 \\
PEG 6000 & $1: 2$ & 400 \\
\hline
\end{tabular}

$\mathrm{pH}$ was 5.6. These conditions alter the dissolution properties of the effective agent: lower temperature and $\mathrm{pH}$ decreases the extent of meloxicam dissolution, although the particle size reduction enhances the extent of dissolution. In the meloxicam PVP-C30 composition, the extent of dissolution after $60 \mathrm{~min}$ increased in case of the co-ground product from $4.1 \pm 0.21 \%$ to $66.2 \pm 4.73 \%$ relative to the physical mixture of the effective agent and the excipient. In the background of this phenomenon stands in one hand the reduction of the particle size (nanonization) and on the other hand the decrease in crystallinity of the effective agent (amorphization). Nanoparticles improve dissolution rate and bioavailability of poorly water-soluble drugs [38-41] owing to increased surface area available for dissolution as described by the Noyes-Whitney equation [42]. The co-grinding technique has already been employed for amorphization of drugs [43,44].

A two-fold enhancement of the extent of meloxicam dissolution was observed in the case of the meloxicam PEG 6000 co-ground product, in which meloxicam is in nanocrystal form. By now, main attention was focussed on size and related surface area. It was recently reported that the interfacial reaction resistance is getting the velocity determining parameter for crystals below $1 \mu \mathrm{m}$. Design of nanocrys- tals with faster interfacial reaction can further enhance the dissolution velocity [45]. In addition, nanomaterials possess improved adhesiveness to biological membranes [7]. The extent of meloxicam dissolution after $60 \mathrm{~min}$ in the physical mixture was $4.1 \pm 0.21 \%$, while that for the optimized product was $8.3 \pm 0.08 \%$. In the physical mixtures the excipient had no influence on the extent of meloxicam dissolution, contrary products, which were undergone nanonization with cogrinding process, showed significantly higher extent of dissolution.

Nanonization and amorphization of meloxicam resulted in significantly better dissolution properties in the in vitro dissolution studies under conditions, which mimic the physiological $\mathrm{pH}$ and temperature of the human nose.

Insoluble powders are likely to be effective for nasal systemic drug delivery [46]. The nasal powder formulations enhance systemic bioavailability, and are superior to liquid formulations $[47,48]$ from the aspects of increased chemical stability of the drug, no requirement for preservatives in the formulations, and the feasibility of administering relatively large amounts of drug [49-51].

\section{Conclusions}

This study explored the effects of additives on the co-grinding behavior of the frequently applied NSAID meloxicam in a high-energy planetary ball mill. It was shown that both PVP and PEG as additives can act as efficient excipients in the mechanical size reduction of meloxicam particles. The influence of the grinding parameters: additive type, meloxicam to additive ratio and milling frequency on the product particle size distribution function was studied via a full
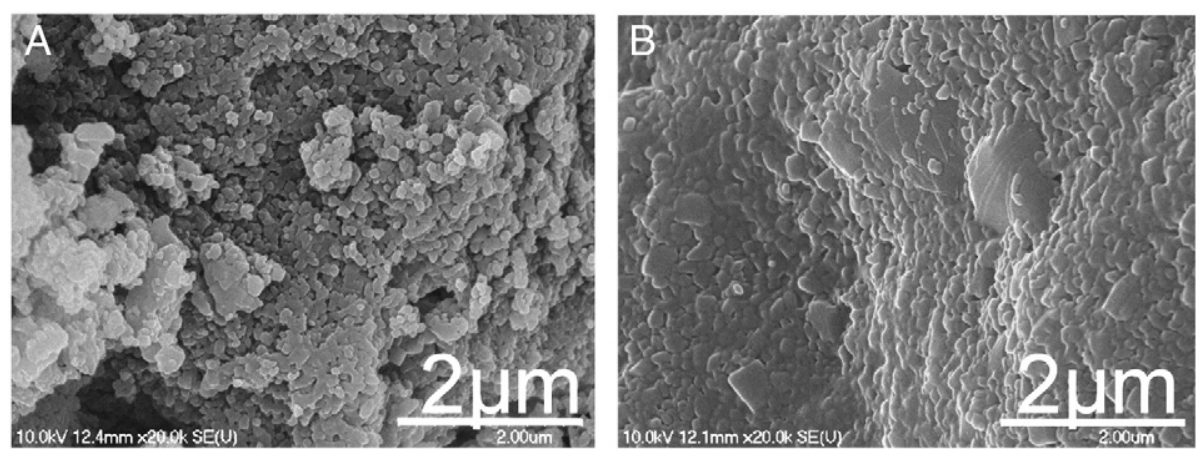

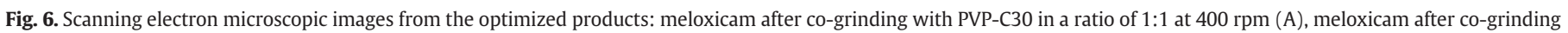
with PEG 6000 in a ratio of 1:2 at $400 \mathrm{rpm}$ (B)/from all of the products PVP and PEG were dissolved with distilled water due to the visualization of meloxicam particles/. 

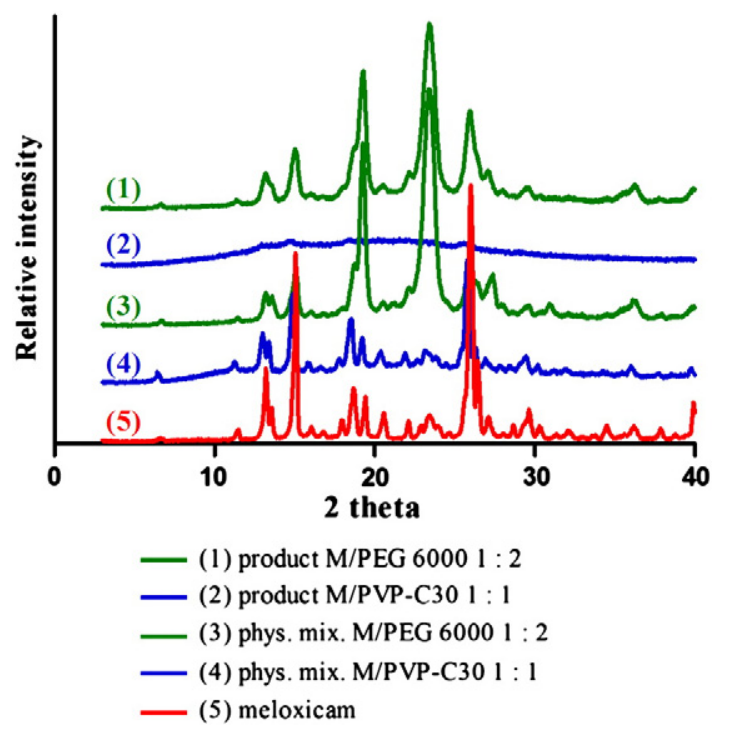

Fig. 7. X-ray powder diffraction spectra of meloxicam (5), physical mixtures $(4,3)$ and products of meloxicam co-grinded with PVP-C30 (2), meloxicam with PEG 6000 (1).

factorial design. Optimum grinding parameter sets for the nitrogencontaining additive PVP (meloxicam to PVP-C30 ratio $=1: 1$, rotation frequency $400 \mathrm{rpm}$ ) and for nitrogen-free PEG 6000 (meloxicam to PEG $6000=1: 2$, rotation frequency $400 \mathrm{rpm}$ ) were identified.

XRPD analysis indicated that the optimized products contained amorphous meloxicam nanoparticles in the PVP-C30 composition, although meloxicam nanocrystals could be detected in the samples which contained PEG 6000. The dissolution properties are also significantly increased under nasal conditions ( $\mathrm{pH} 5.1$, temperature $30^{\circ} \mathrm{C}$ ), especially in the case of the amorphous product. These dry powder systems can offer novel opportunities in systemic nasal drug delivery.

These products are suitable for further investigations in in vitro cell culture models, in ex vivo tissue models and in in vivo animal experiments with the aim of intranasal systemic drug delivery.

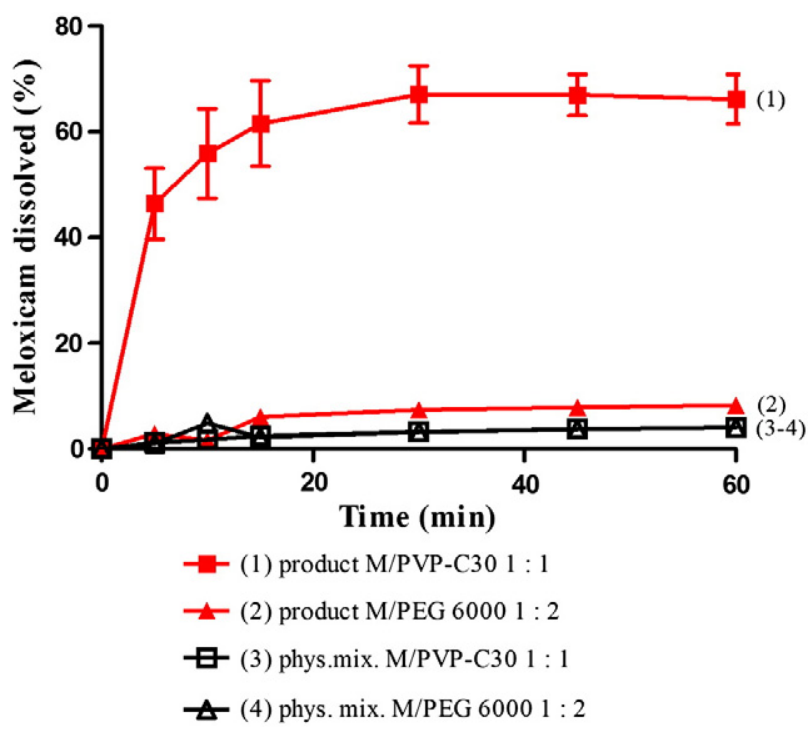

Fig. 8. The extent of meloxicam dissolution in the optimized products and in the physical mixtures, dissolution circumstances: $\mathrm{pH} 5.6 \pm 0.1,30 \pm 0.5^{\circ} \mathrm{C}$.

\section{Acknowledgement}

This work was supported by the TÁMOP research project TÁMOP4.2.1/B-09/1/KONV-2010-0005 and the OTKA-NNF 78920 project.

\section{References}

[1] M.J. Alonso, Nanomedicines for overcoming biological barriers, Biomed. Pharmacother. 58 (2004) 168-172.

[2] A. Graf, E. Ablinger, S. Peters, A. Zimmer, S. Hook, T. Rades, Microemulsions containing lecithin and sugar-based surfactants: nanoparticle templates for delivery of proteins and peptides, Int. J. Pharm. 350 (2008) 351-360.

[3] W.H. De Jong, P.J.A. Borm, Drug delivery and nanoparticles: applications and hazards, Int. J. Nanomed. 3/2 (2008) 133-149.

[4] H. Chen, C. Khemtong, X. Yang, X. Chang, J. Gao, Nanonization strategies for poorly water-soluble drugs, Drug Discov. Today (2010), doi:10.1016/j.drudis.2010.02.009.

[5] J. Brooking, S.S. Davis, L. Illum, Transport of nanoparticles across the rat nasal mucosa, J. Drug Target 9 (2001) 267-279.

[6] M. Rawat, D. Singh, S. Saraf, Nanocarriers: promising vehicle for bioactive drugs, Biol. Pharm. Bull. 29/9 (2006) 1790-1798.

[7] R. Shegokar, R.H. Müller, Nanocrystals: industrially feasible multifunctional formulation technology for poorly soluble actives, Int. J. Pharm. 399 (2010) 129-139.

[8] C.M. Keck, R.H. Müller, Drug nanoparticles of poorly soluble drugs produced by high pressure homogenisation, Eur. J. Pharm. Biopharm. 62 (2006) 3-16.

[9] O.d. Vegt, H. Vromans, J.d. Toonder, K.v.d.V. Maarschalk, Influence of flaws and crystal properties on particle fracture in a jet mill, Powder Technol. 191 (2009) $72-77$.

[10] G. Delagrammatikas, M. Delagrammatikas, S. Tsimas, Particle size distributions a new approach, Powder Technol. 176 (2007) 57-65.

[11] H. Kubo, T. Osawa, K. Takashima, M. Mizobe, Enhancement of oral bioavailability and pharmacological effect of by micronization in co-ground mixture with d-mannitol, Biol. Pharm. Bull. 19 (1997) 741-747.

[12] G.G. Liversidge, K.C. Cundy, Particle size reduction for improvement of oral bioavailability of hydrophobic drugs: absolute oral bioavailability of nanocrystalline danazol in beagle dogs, Int. J. Pharm. 125 (1995) 91-97.

[13] M. Sugimoto, T.S. Okagaki, S. Narisawa, Y. Koida, K. Nakajima, Improvement of dissolution characteristics and bioavailability of poorly water-soluble drugs by novel cogrinding method using water-soluble polymer, Int. J. Pharm. 160 (1998) 11-19.

[14] T. Yamada, N. Saito, T. Imai, M. Otagiri, Effect of grinding with hydroxypropyl cellulose on the dissolution and particle size of a poorly water-soluble drug, Chem. Pharm. Bull. 47 (1999) 1311-1313.

[15] G:G. Liversidge, K.C. Cundy, J. Bishop, D. Czekai, Surface modified drug nanoparticles, US Patent (1992) 5,145,684.

[16] B.E. Rabinow, Nanosuspensions in drug delivery, Nat. Rev. Drug Discov. 3 (2004) 785-796.

[17] K. Moribe, A. Pongpeerapat, Y. Tozuka, K. Yamamoto, Drug nanoparticle formation from drug/HPMC/SDS ternary ground mixtures, Pharmazie 61 (2006) 97-101.

[18] C. Zapata, C. Frances, N. Le Bolay, S. Molina-Boisseau, Production of small composite particles by co-grinding in a media mill. Characterization of the granulometric and the mechanical properties, Trans. IChemE, Part A, Ch. E. R. D. 82 (A5) (2004) 631-636.

[19] M. Barzegar-Jalali, H. Valizadeh, M.-R. Siahi Shadbad, K. Adibkia, G. Mohammadi, A. Farahani, Z. Arash, A. Nokhodchi, Cogrinding as an approach to enhance dissolution rate of a poorly water-soluble drug (gliclazide), Powder Technol. 197 (2010) 150-158.

[20] Á. Kukovecz, D. Méhn, E. Nemes-Nagy, R. Szabó, I. Kiricsi, Optimization of CCVD synthesis conditions for single-wall carbon nanotubes by statistical design of experiments (DoE), Carbon 43 (2005) 2842-2849.

[21] S.L.A. Hennart, M.C. Domingues, W.J. Wildeboer, P. van Hee, G.M.H. Meesters, Study of the process of stirred ball milling of poorly water soluble organic products using factorial design, Powder Technol. 198 (2010) 56-60.

[22] M. Fahmy, Ca-alginate beads loaded with meloxicam: effect of alginate chemical composition on the properties of the beads and ulcerogenicity of the drug, J. Drug Del. Sci. Technol. 16 (2006) 183-189.

[23] G. Hanft, D. Turck, S. Scheuerer, R. Sigmund, Meloxicam oral suspension: a treatment alternative to solid meloxicam formulations, Inflamm. Res. 50 (2001) 35-37.

[24] R. Ambrus, P. Kocbek, J. Kristl, R. Sibanc, R. Rajkó, P. Szabó-Révész, Investigation of preparation parameters to improve the dissolution of poorly water-soluble meloxicam, Int. J. Pharm. 381 (2009) 153-159.

[25] M. Jafar, M.H.G. Dehgan, A. Shareef, Enhancement of dissolution and antiinfammatory effect of meloxicam using solid dispersions, Int. J. App. Pharm. 2/1 (2010) 22-27.

[26] T.P. Shakhtshneider, M.A. Vasiltchenko, A.A. Politov, V.V. Boldyrev, The mechanochemical preparation of solid disperse systems of ibuprofen-polyethylene glycol, Int. J. Pharm. 130 (1996) 25-32.

[27] K. Ioth, A. Pongpeerapat, Y. Tozuka, T. Oguchi, K. Yamamoto, Nanoparticle formation of poorly water-soluble drugs from ternary ground mixtures with PVP and SDS, Chem. Pharm. Bull. 51 (2) (2003) 171-174.

[28] L.S. Taylor, G. Zografi, Spectroscopic characterization of interactions between PVP and indomethacin in amorphous molecular dispersion, Pharm. Res. 14 (1997) 1691-1698. 
[29] T. Watanabe, S. Hasegawa, N. Wakiyama, A. Kusai, M. Senna, Comparison between polyvinylpyrrolidone and silica nanoparticles as carriers for indomethacin in solid state dispersion, Int. J. Pharm. 250 (2003) 283-286.

[30] R. Smajda, Á. Kukovecz, Z. Kónya, I. Kiricsi, Structure and gas permeability of multi-wall carbon nanotube buckypapers, Carbon 45/6 (2007) 1176-1184.

[31] M. Daranyi, Á. Kukovecz, E. Horváth, Z. Kónya, I. Kiricsi, Fine tuning the coverage of a titanate nanowire layer on a glass substrate, Chem. Phys. Lett. 460 (1-3) (2008) 191-195.

[32] J.A. Melero, G. Calleja, F. Martinez, R. Molina, M.I. Pariente, Nanocomposite $\mathrm{Fe}_{2} \mathrm{O}_{3} /$ SBA-15: an efficient and stable catalyst for the catalytic wet peroxidation of phenolic aqueous solutions, Chem. Eng. J. 131 (1-3) (2007) 245-256.

[33] M.D. Abramoff, P.J. Magelhaes, S.J. Ram, Image processing with image, J. Biophotonics Int. 11/7 (2004) 36-42.

[34] R. Remias, Á. Kukovecz, M. Daranyi, G. Kozma, S. Varga, Z. Kónya, I. Kiricsi, Znglycerolate microstacks, Eur. J. Inorg. Chem. 24 (2009) 3622-3627.

[35] C. Zapata-Massot, C. Frances, N. Le Bolay, On the use of scanning electron microscopy for the modelling of co-grinding kinetics in a tumbling ball mill Powder Technol. 143-144 (2004) 215-229.

[36] J. Alkebro, S. BeHgin-Colin, A. Mocellin, R. Warren, Modeling high-energy ball milling in the alumina-yttria system, J. Solid State Chem. 164 (2002) 88-97.

[37] P.P. Chattopadhyay, I. Manna, S. Talapatra, S.K. Pabi, A mathematical analysis of milling mechanics in a planetary ball mill, Mater. Chem. Phys. 68 (2001) 85-94.

[38] R.H. Muller, A. Akkar, Drug nanocrystals of poorly soluble drugs, in: J.A. Schwarz, C. Contescu, K. Putyera (Eds.), Encyclopedia of Nanoscience and Nanotechnology, Marcel Dekker, New York, 2004, pp. 627-638.

[39] V.B. Patravale, A.A. Date, R.M. Kulkarni, Nanosuspensions: a promising drug delivery strategy, J. Pharm. Pharmacol. 56 (2004) 827-840.

[40] M. Mosharraf, C. Nystrom, The effect of particle size and shape on the surface specific dissolution rate of micronized practically insoluble drugs, Int. J. Pharm. 122 (1995) 35-47.
[41] F. Kesisoglou, S. Panmai, Y. Wu, Nanosizing - oral formulation development and biopharmaceutical evaluation, Adv. Drug Deliv. Rev. 5916 (2007) 31-44.

[42] A.A. Noyes, W.R. Whitney, The rate of solution of solid substances in their own solutions, J. Am. Chem. Soc. 19 (1897) 930-934.

[43] M. Senna, S. Nakayama, Preparation and properties of nano-amorphous organic and inorganic particles via chemical and mechanochemical routes, J. Alloys Compd. 483 (2009) 265-270.

[44] R.S. Dhumal, S.V. Biradar, S. Yamamura, A.R. Paradkar, P. York, Preparation of amorphous cefuroxime axetil nanoparticles by sonoprecipitation for enhancement of bioavailability, Eur. J. Pharm. Biopharm. 70 (2008) 109-115.

[45] M.T. Crisp, C.J. Tucker, T.L. Rogers, R.O. Williams III, K.P. Johnston, Turbidimetric measurement and prediction of dissolution rates of poorly soluble drug nanocrystals, J. Control. Release 117 (2007) 351-359.

[46] F. Ishikawa, M. Murano, M. Hiraishi, T. Yamaguchi, I. Tamai, A. Tsuji, Insoluble powder formulation as an effective nasal drug delivery system, Pharm. Res. 19 (2002) No. 8.

[47] N. Fransén, S. Bredenberg, E. Björk, Clinical study shows improved absorption of desmopressin with novel formulation, Pharm. Res. 26 (2009) 1618-1625.

[48] N. Fransén, E. Björk, C. Nyström, Development and characterisation of interactive mixtures with a fine-particulate mucoadhesive carrier for nasal drug delivery, Eur. J. Pharm. Biopharm. 67 (2007) 370-376.

[49] F. Ishikawa, M. Katsura, I. Tamai, A. Tsuji, Improved nasal bioavailability of elcatonin by insoluble powder formulation, Int. J. Pharm. 224 (2001) 105-114.

[50] W.A. Lee, B.A. Narog, T.W. Patapoff, Y.J. Wang, Intranasal bioavailability of insulin powder formulations: effect of enhancer-to-protein ratio, J. Pharm. Sci. 80 (1991) 72-729.

[51] N.G.M. Schipper, S.G. Romejin, J.C. Verhoef, F.W.H.M. Merkus, Nasal insulin delivery with dimethyl- $\beta$-cyclodextrin as an absorption enhancer in rabbits: powder more effective than liquid formulations, Pharm. Res. 10 (1993) 682-686. 